\title{
Thermal Barrier Coatings on Copper Substrates for Rocket Applications*
}

\author{
Jana SCHLOESSER ${ }^{* *}$, Tatiana FEDOROVA**, Martin BÄKER** and \\ Joachim RÖSLER ${ }^{* *}$ \\ ** Technische Universität Braunschweig, Institut für Werkstoffe \\ Langer Kamp 8, 38106 Braunschweig, Germany \\ E-mail: j.schloesser@tu-braunschweig.de
}

\begin{abstract}
Currently a new generation of relaunchable space transportation system using liquid hydrogen/ liquid oxygen rocket engines is under development. The inner combustion chamber is exposed to extreme thermal loads and environmental attack during starts. To prevent failure of the cooling channels, a thermal barrier coating to provide thermal and oxidation protection could be applied. Thermal barrier coatings are state of the art for gas turbines and this concept should be transferred to copper substrates in rocket engine applications. The thermomechanical loading conditions are quite different from the gas turbine applications as heat fluxes and temperature gradients are much higher while overall service time is much shorter. As a start for optimization of a suitable coating, a material system known for gas turbines is employed. In this work a thermal barrier coating system is applied by atmospheric plasma spraying to the copper-based high strength alloy $\mathrm{Cu}-1 \% \mathrm{Cr}-0.3 \% \mathrm{Zr}$. The bond coat consists of a NiCrAlY alloy, while partially stabilized zirconia is used as a top coat. Spraying parameter optimization for the new substrate is described. The reached coating system is tested in thermal cycling experiments, where no failure of the coating could be detected. In oxidation experiments good environmental protection of the coating is shown.
\end{abstract}

Key words : Thermal Barrier Coating, Copper Substrate, Rocket Combustion Chamber, Atmospheric Plasma Spraying

\section{Introduction}

Thermal barrier coatings (TBC) are used in gas turbines to protect the material from high gas temperatures. To realize relaunchable space transportation systems, the lifetime of the rocket engines needs to be increased. For this reason the concept of thermal barrier coatings may be transferred to rocket applications. The rocket nozzle experiences extreme thermal loads during starts, and the material could be protected by a coating from very high temperatures and also from the oxidizing environment.

The thermal barrier coating will be applied on the hot gas side of the combustion liner. A schematic is shown in Fig. 1. Copper alloys are employed for their excellent thermal conductivity. Liquid hydrogen is guided through the cooling channels. Therefore extreme thermal

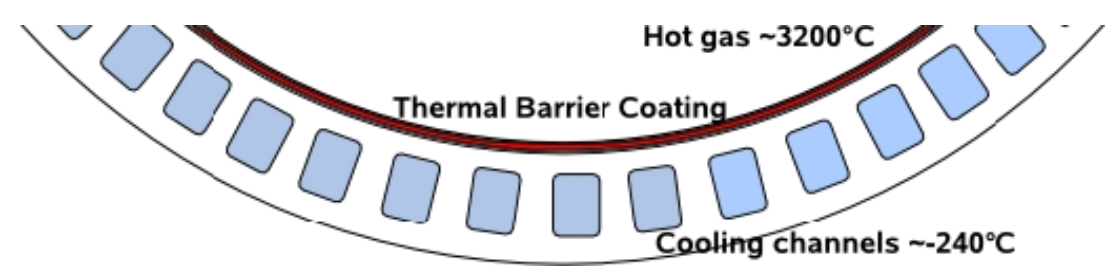

Fig. 1 Thermal Barrier Coating in inner combustion liner.

*Received 6 July, 2009 (No. 09-0311) [DOI: 10.1299/jmmp.4.189]

Copyright (c) 2010 by JSME 


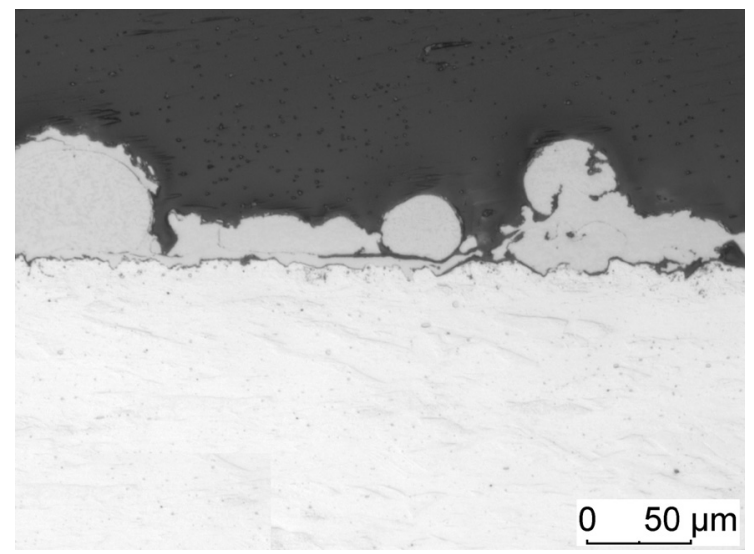

Fig. 2 Micrograph of non-adhering coating applied without substrate heating and $\mathrm{Ar} / \mathrm{H}_{2}$-mixture as working gas.

gradients are imposed on the chamber walls. The cooling channels tend to fail due to the so-called 'dog-house'-effect which is caused by a combination of thermomechanical fatigue and environmental attack ${ }^{(1)}$.

The thermal barrier coating needs to give both, good thermal and oxidation protection. Different approaches have been considered in recent researches. A thermal barrier coating system consisting of a NiCrAlY top coat and a $\mathrm{Cu}-\mathrm{Cr}$ bond coat on $\mathrm{Cu}-8 \% \mathrm{Cr} 4 \% \mathrm{Nb}$-substrate has been investigated ${ }^{(2),(3)}$. These coating were cold-plasma-sprayed and hot-isostatic pressed and showed good adhesion in first thermal cycling tests. Several investigation on $\mathrm{Cu}-\mathrm{Cr}$ alloys as an oxidation protection layer have been performed (e.g. Ref.4 and 5). A TBC system consisting of a MCrAlY bond coat and a zirconia top coat was applied by electron-beam physical vapor deposition and successfully tested ${ }^{(6)}$.

Requirements for TBC systems in rocket engines are quite different to those in gas turbines. Rocket combustion chambers have to withstand heat flows in excess of $100 \mathrm{MW} / \mathrm{m}^{2(6)}$ and an oxidizing atmosphere. Temperature ranges from about $30 \mathrm{~K}$ on the cooling side to $3500 \mathrm{~K}$ on the hot gas side, while the combustion chamber is additionally exposed to a hot gas pressure of about $115 \mathrm{bar}^{(7)}$. To benefit from the good heat conductivity of the copper chamber walls and to avoid hot spots on the hot gas side, the thickness of the thermal barrier coating has to be optimized. The temperature at the uncoated copper surface is assumed to be around $874 \mathrm{~K}^{(2),(3),(6)}$. The temperature at the interface of coated chambers depends on the coating thickness and on the cooling efficiency. Compared to gas turbine applications the number of cycles is less, and the whole operational time range is much shorter. Therefore, totally different coating systems can be imagined.

In this work a standard TBC-system for gas turbines, consisting of a NiCrAlY bond coat and a zirconia top coat, is applied by atmospheric plasma spraying to a copper substrate. These experiments serve as a starting point of an optimization from an existing coating system to a new coating which is especially designed for rocket applications in the future.

\section{Materials and coating parameters}

Besides good heat conduction, the substrate material has to fulfill most demanding requirements such as high tensile strength at high temperatures, sufficient ductility at very low temperatures, thermal fatigue resistance and a certain tolerance against hydrogen atmosphere ${ }^{(6)}$. Because of its good high temperature properties, the commercial alloy $\mathrm{CuCr} 1 \mathrm{Zr}$ (specification number 2.1293) was chosen, which is an age-hardenable copper alloy containing $1 \%$ chromium and $0.3 \%$ zirconium $^{(8)}$. Furthermore, the zirconium content should lead to an increase in ductility after longer time of creep exposure ${ }^{(9)}$.

The bond coat ensures good adhesion between substrate and thermal barrier coating. Furthermore, it has an intermediate coefficient of thermal expansion and therefore reduces thermal 

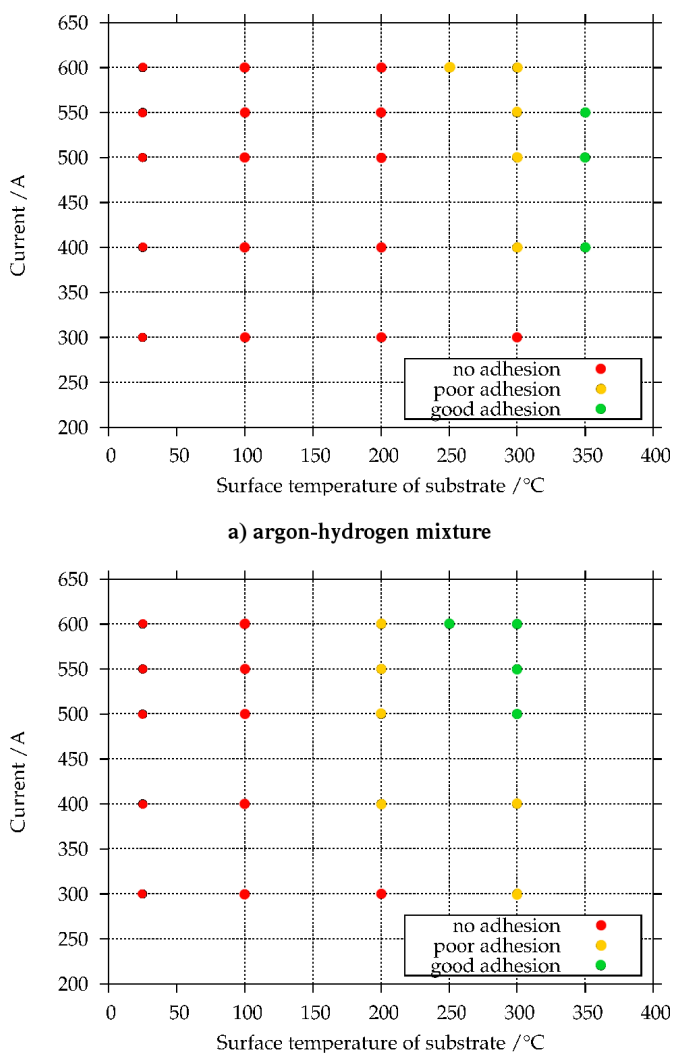

b) argon-nitrogen mixture

Fig. 3 Adhesion of MCrAlY bond coat for different substrate temperatures, current values and working gas mixtures.

strains. Typically, MCrAlY coatings are used (M stands for a metallic element such as Ni or Co). In this study different bond coat materials were used for coating parameter optimization, while for the thermal cycling and oxidation experiments NiCrAlY with $22 \% \mathrm{Cr}, 10 \% \mathrm{Al}$ and $1 \% \mathrm{Y}$ is used. A powder grain size between 10 and $37 \mu \mathrm{m}$ is used for thermal spraying. The substrate surface was corundum-blasted before spraying with a grain size between 60 and $120 \mu \mathrm{m}$.

For the thermal barrier coating ziconia is used because of its low thermal conductivity in combination with a relatively high coefficient of thermal expansion. The zirconia used in this study is partially stabilized with $8 \%$ yttrium oxide to shift phase transition to higher temperatures. The grain size of the spraying powder is between 10 and $40 \mu \mathrm{m}$.

The thermal barrier coating systems are applied by atmospheric plasma spraying. In a first run the bond coat is applied and directly afterwards the ceramic layer is sprayed. The coating parameters for bond coat spraying which are known for nickel-base superalloys, had to be adapted to the new substrate material. The specimens were grit-blasted and cleaned in ethanol before the bond coat was applied. A certain roughness is necessary for a good adhesion. Because of the high affinity to oxygen of copper, the specimens were grit-blasted directly before coating.

Substrate heating for bond coat spraying is required to achieve dense and adhering coatings. In Fig. 2 a micrograph of a non-adhering MCrAlY coating is shown. As copper is prone to oxidation, especially at high temperatures, it is desirable to minimize the substrate temperature. During the first experiments, the bond coat was sprayed with a mixture of argon and hydrogen. In Fig. 3a) the adhesion of the coating depending on the electrical current and on the substrate temperature is shown. Adhesion in this context means, whether is is possible to apply an adhering coating or not. No adhesion testing experiments have been performed so far. Higher currents and higher substrate temperatures yield better adhesion. If the hydrogen is 

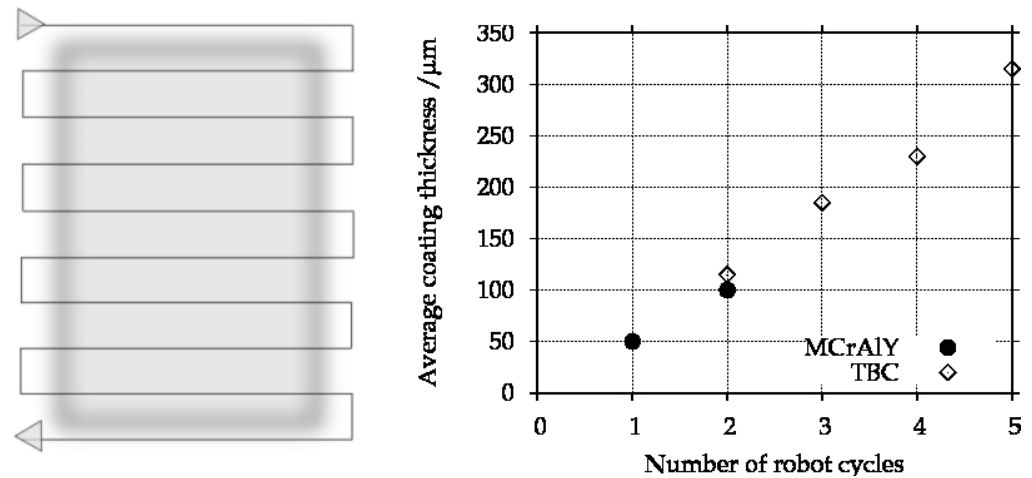

Fig. 4 Robot movement and thickness depending on coating cycles.

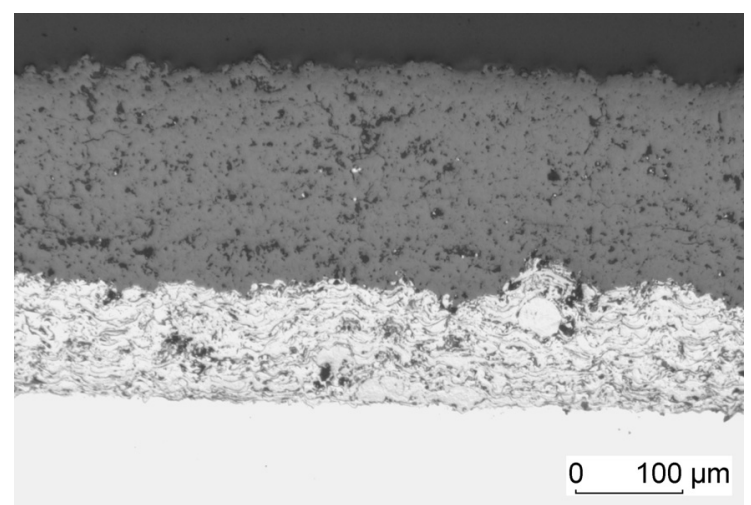

Fig. 5 Micrograph of the applied coating system.

substituted by nitrogen, much better adhesion especially at lower substrate temperatures was observed. The result of these experiments are summarized in Fig. 3b). The observed effect is probably due to the susceptibility of copper to hydrogen. As mentioned above, the substrate temperature should be kept as low as possible. For this reason a mixture of nitrogen and argon was chosen for all of the following experiments for plasma spraying of the bond coat, while a mixture of hydrogen and argon was used for TBC application.

The characteristics of the coating system depending on the coating thickness should be investigated. The easiest way to vary the coating thickness is a variation of the number of robot cycles. The robot holding the plasma torch is programmed to move in a meandering way to coat the whole specimen homogeneously. A schematic of the robot movement is shown in Fig. 4. Microsection investigations show that the coating is homogeneously applied in this way apart from the normal scatter due to the plasma spraying process. The average coating thickness depending on the number of robot cycles is plotted in Fig. 4.

As mentioned above substrate heating during the coating process is required. The best results were obtained by heating the substrate to $523 \mathrm{~K}$ during both coating processes. An electrical current of $600 \mathrm{~A}$ was used and the spraying distance was $1000 \mathrm{~mm}$. These coating parameters and the powder materials described above were applied for all the specimens tested in thermal cycling and oxidation experiments. In Fig. 5 a micrograph of the optimized coating system is shown.

\section{Experimental results}

\subsection{Thermal cycling experiments}

The adhesion of the coating system was investigated in thermal cycling experiments. Due to the difference in the coefficients of thermal expansion, large thermal strains are imposed during heating and cooling of the specimen, which could lead to a spallation of the coating. The coating system described in section 2 was applied and specimens with different average coating thicknesses (between 50 and $100 \mu \mathrm{m}$ for bond coat and between 100 and $300 \mu \mathrm{m}$ for 


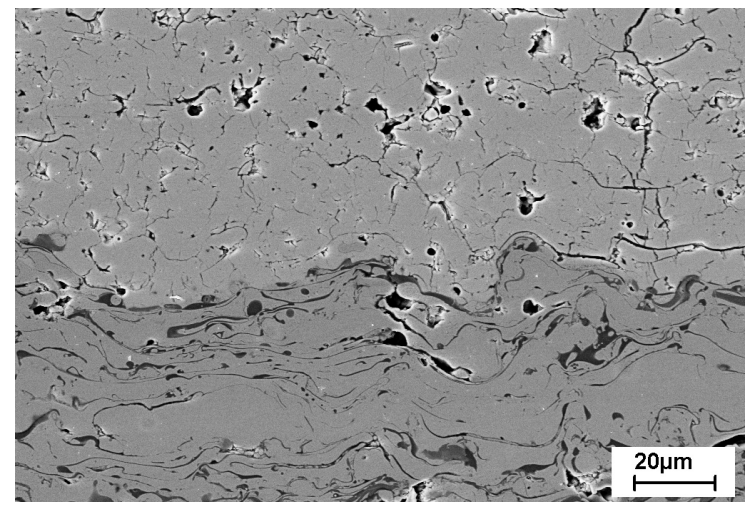

Fig. 6 Interface between bond coat and TBC after 10 thermal cycles without oxide growth.

TBC) were tested.

The specimens were heated in atmospheric air to $873 \mathrm{~K}$. The maximum temperature of the copper in real application is expected to be around this temperature ${ }^{(2),(3),(6)}$. A long holding time at high temperature of 23 hours was chosen to enhance possible oxidation and creep effects in the material. The specimens were cooled in air for one hour and the cycle was repeated. The specimens were visually inspected after each cycle.

After ten cycles no sign of spallation of the coatings was visible. Investigations of microsections did not show any signs of cracks, oxidation of the substrate, or enhanced microcracking. Scanning electron microscopy detcted neither delamination of the coatings nor oxidation products at coating interfaces. As none of the specimens failed, no statement about the influence of coating thicknesses on lifetime can be made yet.

In gas turbine applications failure normally occurs at the interface between bond coat and thermal barrier coating, where a thermally grown oxide (TGO) is formed and enhances thermal stresses ${ }^{(10)}$. In the performed experiment no TGO was formed due to relatively low temperatures at the interface, which can be seen in Fig. 6. In contrast to EB-PVD processes, there is no TGO formed during plasma spraying.

Without TGO formation different failure mechanisms would have to be considered. Because of the short exposure times at high temperatures and relatively low temperatures (compared to gas turbine applications) at the interface thermal mismatch stresses are more important than TGO formation. In the thermal cycling experiments described, no thermal gradient was imposed to the specimens, and the maximum temperature was the one expected for the copper substrate. In real application severe thermal gradients exist (see Section 2). Therefore the maximum temperature at the interface between thermal barrier coating and bond coat was probably significantly underestimated in the cycling experiments. On the other hand the exposure time is extremely short in reality. Experimental set-ups like burner rig tests which impose thermal gradients would have to confirm the lack of bond coat oxidation.

\subsection{Oxidation protection behavior}

Oxidation experiments were performed at $873 \mathrm{~K}$ in atmospheric air for 240 hours. The uncoated copper alloy was severely oxidated, but the bond coat provided good oxidation protection to the substrate. As the thermal barrier coating is porous and therefore permeable to oxygen, it does not contribute to oxidation protection.

At the left side of Fig. 7, oxidation of the substrate at the uncoated edge is visible (originally substrate and coating were in one vertical line) while no oxidation products can be seen in the middle of the specimen. Oxidation only occurs as an edge effect which can be neglected if the area of the specimen is large enough. In real application this effect would not occur because no uncoated edges would exist.

Because of the coating process, zones where the bond coat is thinning exist for the some 


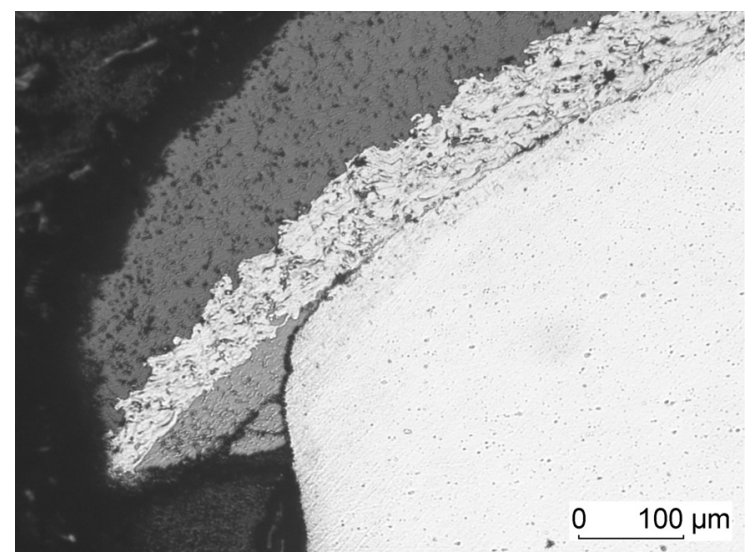

Fig. 7 Oxidation of edge zone of the specimen after $240 \mathrm{~h}$ at $873 \mathrm{~K}$ in atmospheric air.

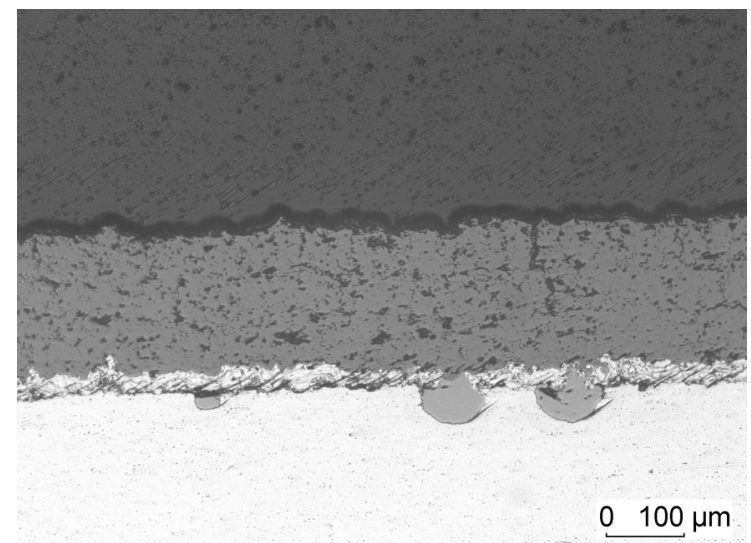

Fig. 8 Oxidation under thinning bond coat after $240 \mathrm{~h}$ at $873 \mathrm{~K}$ in atmospheric air.

specimens. If the bond coat becomes too thin, it is apparently not dense enough and the substrate is partially oxidized which can be seen in Fig. 8. The specimen geometry and the coating process were successfully optimized to avoid this problem.

Generally the applied coating system provides good oxidation protection to the copper substrate.

\section{Conclusions}

Thermal barrier coatings on copper substrates for application in rocket engine combustion chambers were successfully produced by atmospheric plasma spraying. Coating parameters have been adapted to successfully apply thermal barrier coatings with a NiCrAlY bond coat and a zirconia top coat. First thermal cycling experiments show no sign of delamination after ten cycles between $873 \mathrm{~K}$ and room temperature in atmospheric air. No thermal gradients have been imposed during cycling so far. The bond coat provides good oxidation protection to the substrate which could be proved in long term oxidation experiments. No thermally grown oxide was formed neither during cycling nor during oxidation experiments. As failure normally occurs at the interface of the thermally grown oxide in gas turbine applications, failure mechanisms for thermal barrier coatings on nickel-based substrates can possibly not be transferred to coatings on copper substrates. This will be the issue of further research in the future.

\section{Acknowledgement}

Financial support has been provided by the German Research Council (Deutsche Forschungsgemeinschaft - DFG) in the framework of the Sonderforschungsbereich Transregio 40 . 


\section{References}

( 1 ) Riccius, J.R., Haidn, O. And Zametaev, E.B. (2004). Influence of time dependent effects on the estimated life time of liquid rocket chamber walls. AIAA, 2004-3670.

( 2 ) Raj, S.V., Ghosn, L.J., Robinson, C. And Humphrey, D. (2007). High heat flux exposures of coated GRCop-84 substrates. Materials Science and Engineering: A, 457, 300-312.

( 3 ) JAIN, P., RAJ, S.V. And Hemker, K.J. (2007). Characterization of NiCrAlY coatings for a high strength, high conductivity GRCop-84 copper alloy. Acta Materialia, 55, 51035113.

( 4 ) Raj, S.V., Barrett, C., Karthikeyan, J. and Garlick, R. (2007). Comparison of the cyclic oxidation behavior of cold sprayed CuCrAl-coated and uncoated GRCop-84 substrates for space launch vehicles. Surface and Coatings Technology, 201, 7222-7234.

( 5 ) Ogbusi, L. (2003). Protection of Advanced Copper Alloys With Lean Cu-Cr Coatings. NASA Report, NASA CR - 2003-212548.

( 6 ) Schulz, U., Fritscher, K., Peters, M., Greuel, D. and Haidn, O. (2005). Fabrication of TBC-armored rocket combustion chambers by EB-PVD methods and TLP assembling. Science and Technology of Advanced Materials, 6, 103-110.

( 7 ) Greuel, D., Suslov, D., Haidn, O. and Fritscher, K. (2002). Thermal Barrier Coatings for Cryogenic Rocket Engines. AIAA, 2002-4145.

( 8 ) Deutsches Kupferinstitut (2005). Kupferdatenblatt CuCr1Zr.

( 9 ) Baukloh, A., Drehfahl, K., Heubener, U., Rhle, M. (1976). Zeitstandsuntersuchungen an niedrig- und unlegierten Kupferwerkstoffen. Metall, 30, 19-28.

(10) Rösler, J., B̈̈Ker, M. AND Volgmann, M. (2001). Stress state and failure mechanisms of thermal barrier coatings: role of creep in thermally grown oxide. Acta Materialia, 49, 3659-3670. 